\title{
A Case of Tubo-ovarian Abscess due to Salmonella enterica Following an In Vitro Fertilization Attempt
}

\section{In Vitro Fertilizasyon Girişimi Sonrası Gelişen Salmonella enterica Nedenli Bir Tuba-ovaryan Apse Olgusu}

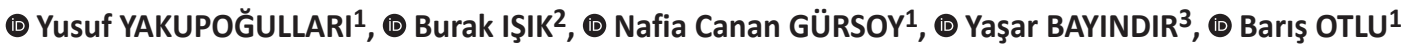 \\ Iinönü University Faculty of Medicine, Department of Medical Microbiology, Malatya, Turkey \\ 2Inönü University Liver Transplantation Institute, Department of General Surgery, Malatya, Turkey \\ 3inönü University Faculty of Medicine, Department of Infectious Diseases and Medical Microbiology, Malatya, Turkey
}

Keywords: In vitro fertilization, adnexa, meropenem, laparascopic surgery, salpingo-oophorectomy

Anahtar Kelimeler: In vitro fertilizasyon, adneks, meropenem, laparaskopik cerrahi, salpingo-ooforektomi

\section{Dear Editor,}

Salmonella are Gram-negative and facultative intracellular bacilli that may cause infections ranging from self-limiting gastroenteritis to typhoid fever ${ }^{[1]}$. Extraintestinal focal infection due to Salmonella is uncommon, and involvement of the genital organs by Salmonella is extremely rare.

Herein, we report a female patient who developed a tuboovarian abscess shortly after in vitro fertilization (IVF) treatment. According to our literature search, tubo-ovarian abscess has been described in only a few patients to date ${ }^{[2,3]}$. To the best of our knowledge, this will be the first case of the adnexal involvement of Salmonella in association with IVF.

In February 2017, a 42-year-old woman was admitted to the general surgery ward of our hospital with right abdominal pain, vomiting, and fever for three days. Her medical history included a two-week hospitalization in our infectious diseases ward due to fever, abdominal pain, vomiting, and diarrhea in November 2016 as well as an IVF attempt performed two weeks before the present application. On physical examination, defense and rebound were positive in the right lower abdomen. Her white blood cell count was measured as $18,000 / \mathrm{ml}$ and
C-reactive protein level was $36 \mathrm{mg} / \mathrm{dl}(0-5 \mathrm{mg} / \mathrm{dl})$. Computerized tomography (CT) scan showed a complicated paraovarian abscess measured $128 \times 76 \mathrm{~mm}$ in size that was filling the pouch of Douglas and showed substantial enlargement compared with a previous CT image performed in December 2016. Figure 1 shows the CT image of the patient showing large adnexal cysts.

Surgery was initiated with a laparoscopic approach but was converted to laparotomy due to widespread pus and adhesions in the lower abdomen. A massive inflamed cyst and free purulent fluid were observed in the pouch of Douglas. The cyst contents were aspirated and a right salpingo-oophorectomy was performed.

Gram-negative, motile, lactose-negative bacilli grew in pus culture. The pathogen was identified as Salmonella subgroup 1 with Vitek MS MaldiTof MS device (Bio Mérieux, France) and confirmed as Salmonella enterica with 16s rDNA sequencing in an AbiPrism 310 (Applied Biosystems, US) DNA sequencing device. Antimicrobial susceptibility test was done with broth microdilution method, and the isolated pathogen was found susceptible to all tested antimicrobials such as ampicillin, ciprofloxacin, chloramphenicol, and trimethoprim/ sulphamethoxazole ${ }^{[4]}$.

Cite this article as: Yakupoğulları Y, Işık B, Gürsoy NC, Bayındır Y, Otlu B. A Case of Tubo-ovarian Abscess due to Salmonella enterica Following an In Vitro Fertilization Attempt. Mediterr J Infect Microb Antimicrob. 2019;8:22. 


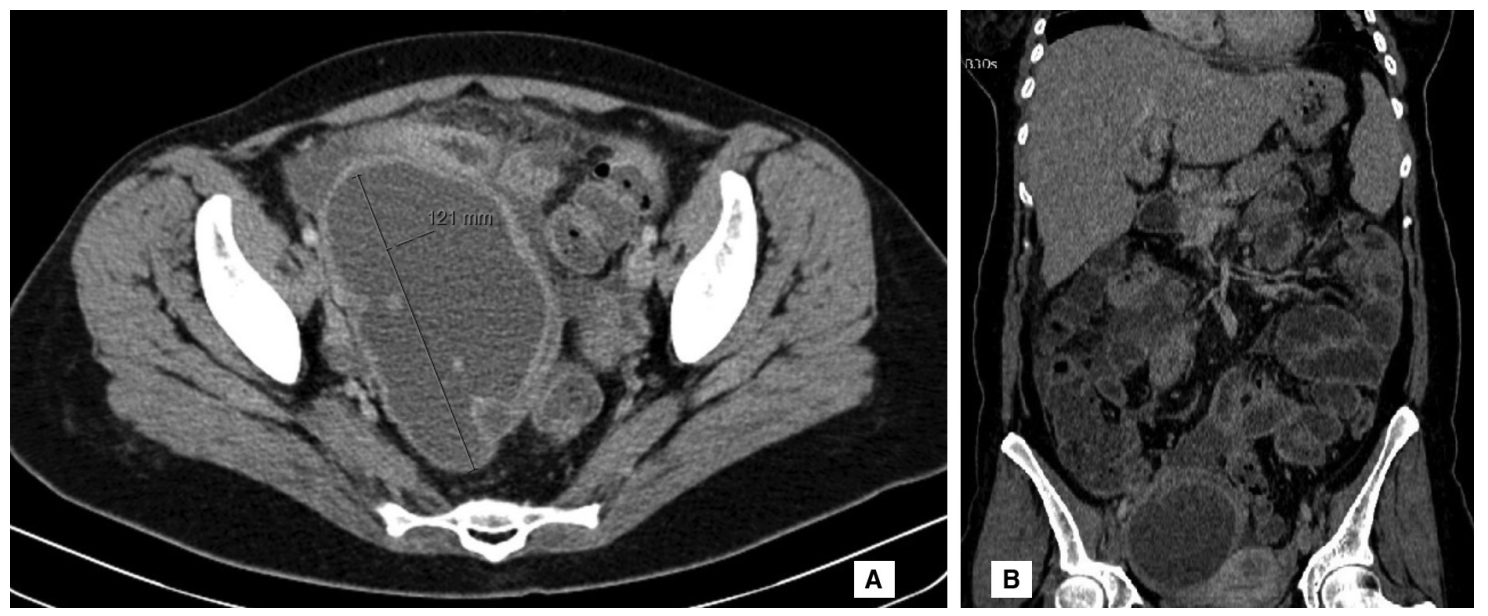

Figure 1. Axial contrast-enhanced computerized tomography slice $(A)$ demonstrates a right paraovarian abscess with largest diameter of $12 \mathrm{~cm}$. Coronal reformatted computerized tomography image (B) shows the abscess and a submucosal myoma of $25 \mathrm{~mm}$ in diameter is also seen

Although a significant pathogen was not identified in blood and stool cultures, Salmonella DNA was detected in the patient's fecal sample using a multiplex PCR assay (FilmArray Gastrointestinal Pathogens, BioFire Diagnostic LLC, US). She completely recovered with postoperative meropenem treatment.

In vitro fertilization is an assisted reproductive technique to help women who cannot conceive naturally to become pregnant. In the IVF procedure, the patient's ovaries are stimulated with gonadotropin-releasing hormones, then the appropriate oocytes are collected with a minor invasive procedure. After in vitro insemination, the developing embryo is placed into the uterine cavity. Studies have reported that the frequency of IVF-related infectious complications is about $0.3-0.6 \%$, with pelvic abscess accounting for nearly half of these cases ${ }^{[5]}$.

Most of the pathogens causing pelvic infection are sexuallytransmitted organisms which progress to endometrium or salpinx from the vagina in healthy women. However, very limited information exists about the pathogens causing pelvic infections and their sources in women undergoing IVF. Studies have reported that the organisms could be introduced to the patients' pelvic organs at two stages of IVF: during the collection of mature oocytes from the ovaries, or during implantation of the zygote or embryo into the uterus. Peters et al. ${ }^{[6]}$ speculated that activation of quiescent bacteria within the fallopian tubes from a previous infection or introduction of bacterialaden secretions or air into the fallopian tubes during embryo transfer may be the mechanisms underlying the development of pelvic infection in these patients. Furthermore, Bennett et al. ${ }^{[7]}$ reported that the causative agents of IVF-related infections may originate primarily from the vaginal tract (by the ascending route); or rarely, from the intestinal tract via incidental puncture of the bowel with the follicular aspiration needle.
In this study, we report a female patient who developed adnexal abscess following IVF due to an uncommon pathogen, Salmonella enterica, which has not been reported previously. Since she was hospitalized for febrile and gastrointestinal symptoms about 50 days before the IVF procedure, we believe that this preexisting mass in the right adnexa was most likely infected by Salmonella during the IVF procedure. Regarding the possible mechanisms mentioned above, we believe that Salmonella was introduced into the right adnexa via the oocyte collection needle, which may have been contaminated in a possible stick injury to the bowel during oocyte collection. This mechanism seemed most likely for our patient, as we determined that she was a gastrointestinal Salmonella carrier.

Studies have shown that the hematogenous route was one of the most common routes for development of focal genital tract Salmonella infections ${ }^{[8,9]}$. However, this route is particularly common in immune-compromised persons. In addition, as Salmonella can be excreted with stool and urine (at some stages of typhoid fever), it is also possible for this organism to cause abscess by ascendant route from vaginal colonization which is likely to develop due to the perianal proximity to the rectum or urinary contamination of the vagina.

Regarding the invasive characteristics of the pathogen, fortunately our patient did not develop life-threatening complications due to the pathogen, such as septic shock, peritonitis, or pelvic inflammatory disease. However, she lost her right ovary as a result of this infection, and this outcome impaired her fertility.

Herein, in addition to reporting the first case of tubo-ovarian abscess caused by Salmonella in a patient with IVF, we also intended to focus on the possible dynamics of infection development. Therefore, well-documented cases will provide 
valuable data for professionals in reproductive medicine to improve IVF methods.

\section{Ethics}

Informed Consent: Consent form was filled out by the presented case.

Peer-review: Internally and externally peer-reviewed.

\section{Authorship Contributions}

Surgical and Medical Practices: B.I., Y.B., Concept: Y.Y., B.O., Design: Y.Y., B.O., N.C.G., Data Collection or Processing: B.I., Y.B., Y.Y., Analysis or Interpretation: Y.Y., N.C.G., Literature Search: Y.Y., Writing: Y.Y., B.O., N.C.G., B.I.

Conflict of Interest: No conflict of interest was declared by the authors.

Financial Disclosure: The authors declared that this study received no financial support.

\section{References}

1. Pearson, RD, Guerrant RL. Enteric fever and other causes of abdominal symptoms with fever. In: G. L. Mandell, J. E. Bennett, and R. Dolin (ed.),
Principles and practice of infectious diseases, $5^{\text {th }}$ ed. Churchill Livingstone, New York, N.Y. 2000.

2. Selvam EM, Sridevi TA, Menon M, Rajalakshmi V, Priya RL. A Case of Salmonella enterica serovar typhi tubo ovarian abscess. J Obstet Gynaecol India. 2015;65:278-80.

3. Guler S, Oksuz H, Cetin GY, Kokoglu OF. Bilateral tubo-ovarian abscess and sepsis caused by Salmonella in patients with systemic lupus erythematosus. BMJ Case Rep. 2013:10.

4. The European Committee on Antimicrobial Susceptibility (EUCAST). 2015. Testing breakpoint tables for interpretation of MICs and zone diameters. Version 7.1. Last Accessed Date: 1 November 2018. Available from: www. eucast.org/clinical_breakpoints.

5. Bergh T, Lundkvist 0 . Clinical complications during in-vitro fertilization treatment. Hum Reprod. 1992;7:625-6.

6. Peters AJ, Hecht B, Durinzi K, DeLeon F, Wentz AC. Salpingitis or oophoritis: what causes fever following oocyte aspiration and embryo transfer? Obstet Gynecol. 1993;81:876-7.

7. Bennett SJ, Waterstone JJ, Cheng WC, Parsons J. Complications of transvaginal ultrasound-directed follicle aspiration: a review of 2670 consecutive procedures. J Assist Reprod Genet. 1993;10:72-7.

8. Fernández Guerrero ML, Ramos JM, Núñez $A$, Cuenca $M$, de Górgolas $M$. Focal infections due to non-typhi Salmonella in patients with AIDS: report of 10 cases and review. Clin Infect Dis. 1997;25:690-7.

9. Al-Obeid K, Al Khalifan NN, Jamal W, Kehinde EO, Rotimi VO. Epididymoorchitis and testicular abscess caused by Salmonella enteritidis in immunocompromised patients in Kuwait. Med Princ Pract. 2006;15:305-8. 